\title{
Intraoperative apical ventricular septal defect closure using a modified Rashkind double umbrella
}

\author{
R R Chaturvedi, D F Shore, M Yacoub, A N Redington
}

\begin{abstract}
Objective-To demonstrate the safety and efficacy of intraoperative apical ventricular septal defect (VSD) closure using a modified Rashkind double umbrella. Design-Descriptive study of all patients in whom intraoperative device closure of apical VSDs was attempted.

Setting-A tertiary referral centre.

Patients-Four patients with an apical VSD requiring closure, during the period January 1993 to May 1995.

Interventions-Intraoperative placement of a modified Rashkind umbrella.

Results-Four successful placements resulting in apical VSD closure, as judged by transoesophageal colour flow mapping. Three patients received a $17 \mathrm{~mm}$ and one a $12 \mathrm{~mm}$ umbrella. Early complete closure was acheived in three patients. There was a small residual leak around the $12 \mathrm{~mm}$ device that had resolved at 5 month follow up. There was one early death, which was unrelated to VSD closure.
\end{abstract}

Conclusion-Apical ventricular septal defects can be closed safely and effectively with intraoperative use of a modified Rashkind umbrella.

(Heart 1996;76:367-369)

Keywords: ventricular septal defect closure; interventional cardiology; Rashkind double umbrella
Effective closure of apical trabecular ventricular septal defects (VSDs) is a surgical challenge and remains a significant cause of failure in surgical series. ${ }^{12}$ Even with the use of a left ventriculotomy, successful closure is not assured and is performed at the expense of the long-term sequelae of a left ventricular scar.

Transcatheter closure using a double-disc device is a novel approach to VSD closure. ${ }^{34}$ Bridges $e t$ al used the Lock clamshell for preoperative closure of muscular VSDs with great success. ${ }^{3}$ This method, however, requires relatively large sheaths, precluding its use in many infants and small children. When the same group tried to overcome this by attempting intraoperative device placement, the results were disappointing. ${ }^{5}$

We report the successful intraoperative closure of an apical VSD in four patients using a modified Rashkind umbrella.

\section{Patients and methods}

In the first patient, an adult, an unexpected apical VSD was found at operation. The remaining three patients were referred preoperatively for intraoperative device closure, to avoid the anticipated requirement for a left ventriculotomy for VSD closure (table).

\section{METHODS}

The umbrella was modified as previously described by producing a gentle bend in the arms. ${ }^{4}$ The inflexible metal pod and shaft of
Department of Paediatrics, Royal Brompton Hospital, London

R R Chaturvedi

D F Shore

$M$ Yacoub

A N Redington

Correspondence to: Dr A N Redington, Department of Paediatrics, Royal Brompton Hospital, Sydney Street, London SW3 6NP.

Accepted for publication 16 May 1996
Data on four patients in whom a modified Rashkind double umbrella was used

\begin{tabular}{|c|c|c|c|c|c|}
\hline Patient & $\begin{array}{l}\text { Age } \\
(y)\end{array}$ & $\begin{array}{l}\text { Weight } \\
(\mathrm{kg})\end{array}$ & Diagnosis & Surgery & Result \\
\hline 1 & 0.5 & $4 \cdot 6$ & $\begin{array}{l}\text { TGA, PS, VSD (midmuscular, } \\
\text { apical } 7 \mathrm{~mm} \text { ) }\end{array}$ & $\begin{array}{l}\text { Mustard's procedure, } \\
\text { mid-muscular VSD closure }\end{array}$ & No leak \\
\hline 2 & $1 \cdot 7$ & $12 \cdot 5$ & $\begin{array}{l}\text { Previous coarctation repair } \\
\text { +PA band for apical } \\
\text { VSD }(6 \mathrm{~mm})\end{array}$ & PA deband & No leak \\
\hline $3^{\star}$ & $3 \cdot 7$ & 13 & $\begin{array}{l}\text { Previous Pa band for multiple } \\
\text { VSD (apical } 5 \mathrm{~mm} \text { ) }\end{array}$ & PA deband & $\begin{array}{l}\text { Small leak initially, } \\
\text { none at } 5 \text { months }\end{array}$ \\
\hline 4 & 29 & 74 & $\begin{array}{l}\text { CCTGA, PS, VSD } \\
\text { (high muscular, apical } 6 \mathrm{~mm} \text { ), } \\
\text { Ebstein's malformation of the } \\
\text { left atrioventricular valve, } \\
\text { pacemaker for complete } \\
\text { heart block }\end{array}$ & $\begin{array}{l}\text { LV to PA conduit, patch } \\
\text { closure of high muscular VSD }\end{array}$ & $\begin{array}{l}\text { No leak, died } 6 \text { days } \\
\text { later }\end{array}$ \\
\hline
\end{tabular}

*This patient received a $12 \mathrm{~mm}$ device, all others a $17 \mathrm{~mm}$ device.

TGA, transposition of the great arteries; PS, pulmonary stenosis; CCTGA, congenitally corrected transposition of the great arteries. 
the normal delivery system makes manipulation almost impossible. For this reason, the delivery system was stripped, and the umbrella front-loaded ${ }^{67}$ into a short segment (about $15 \mathrm{~cm}$ ) of pre-shaped guiding sheath. The umbrella was passed to the tip of the sheath (shaped to have an approximate right-angle bend, close to its tip). This had two advantages; first, a smaller sheath could be used ( $9 \mathrm{~F}$ and $6 \mathrm{~F}$ for the $17 \mathrm{~mm}$ and $12 \mathrm{~mm}$ devices respectively), and secondly, the introducer is customised to the size and position of the defect, so reducing the amount of cardiac manipulation required.

While the patient was on cardiopulmonary bypass, the curved portion of the long sheath was passed through the defect, via a right atriotomy, into the left ventricle. The delivery wire was then pushed forwards $6-7 \mathrm{~mm}$ (12 $\mathrm{mm}$ device) or $9-10 \mathrm{~mm}$ (17 mm device) in order to deploy the distal umbrella in the left ventricular cavity. The sheath was then drawn back until resistance was felt as the distal arms made contact with the left ventricular aspect of the intraventricular septum. The sheath was then pulled back over the delivery wire, allowing the proximal umbrella to open. The device was then released (figure). In the second patient in the series the device was partially displaced because of considerable rocking during de-airing. The device was repositioned and a single stitch was placed to hold the device on the right ventricular aspect. This is now done routinely. Transoesophageal echocardiography helped to confirm the position of the distal umbrella during deployment in two patients, but was performed in all patients during rewarming after the procedure to confirm the device position and assess the haemodynamic result.

\section{Results}

The process of umbrella closure was uncomplicated and although not formally measured,
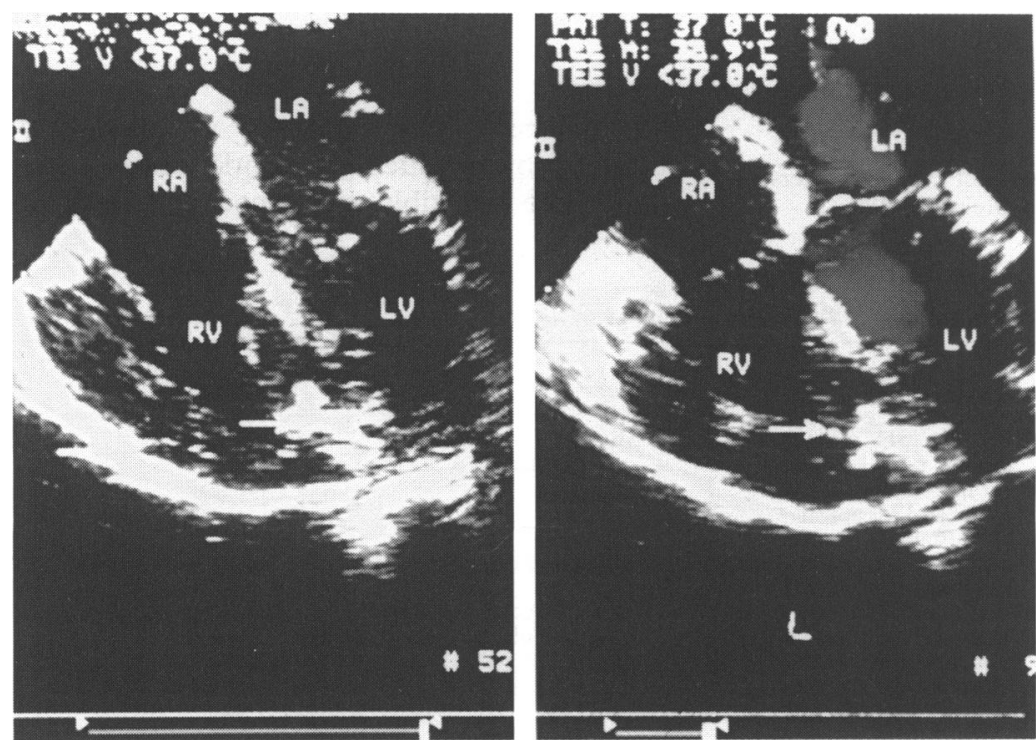

Transgastric short-axis view showing an apical ventricular septal defect after closure with $17 \mathrm{~mm}$ Rashkind double umbrella in systole (right panel) and diastole (left panel). There was no leak on colour-flow mapping immediately after deployment. the procedure time was less than five minutes in all cases. This compares very favourably with the much longer procedure times when the equivalent manoeuvre is attempted in the catheterisation laboratory. All four patients had technically successful apical VSD closure as demonstrated by colour flow mapping on transoesophageal echocardiography. There was a small residual leak in patient 3 who had a $12 \mathrm{~mm}$ device placed. This was haemodynamically insignificant however, and had closed when he was reviewed five months postoperatively. Patient 4 died on the sixth postoperative day from multiorgan failure secondary to low cardiac output. His apical VSD closure was a technical success as confirmed by postmortem examination. There was complete closure of the defect with no obvious antemortem thrombus formation, and no evidence of neointima formation at this early stage.

\section{Discussion}

Apical VSD closure using left ventriculotomy should be avoided. ${ }^{18}$ Hanna and coworkers found that of 24 patients with a mean follow up of 4.8 years, eight had moderate to severe left ventricular impairment, one had required cardiac transplantation for left ventricular failure, one had died, and three had large apical aneurysms. ${ }^{8}$ In four (17\%) patients there was a significant residual VSD.

These poor surgical results prompted the development of alternative strategies to avoid left ventriculotomy, including the use of fibrin glue and double-disc devices. Leca and colleagues reported their experience with fibrin seal in 15 patients with multiple VSD. ${ }^{9}$ Satisfactory results were obtained in most, but their study identified a major problem with this method. Systemic embolism caused by the fibrin glue extending into the left ventricular cavity led to a postoperative transient hemiplegia in one patient and another died unexpectedly 48 hours postoperatively, possibly as a consequence of a coronary artery embolism.

The only previous report of intraoperative VSD closure using a double-disc device was similarily discouraging. Fishberger et al reported adequate closure in only one of 10 children who underwent intraoperative VSD closure with the Lock clamshell. There were five deaths (four early, one late), two of the early deaths occurred in patients described as moribund preoperatively, and the late death occurred before closure of a residual VSD could be performed. Two further children had inadequate VSD closure and required postoperative transcatheter device placement. Two of the three children with successful intraoperative device placement were left with a $\mathrm{Qp}: \mathrm{Qs}=2$. This contrasts with the excellent results from the same group using preoperative transcatheter closure ${ }^{3}$ and may be related to patient selection; most of those undergoing intraoperative closure had multiple ventricular septal defects or a "Swiss cheese" septum.

We have demonstrated that intraoperative VSD closure with a modified Rashkind double umbrella is feasible and effective for isolated 
apical VSD. A single device sufficed in the four patients described, but this technique could be extended to those with multiple defects. The technique is particularly appropriate in small children and infants in whom transcatheter closure is more difficult and the need for a left ventriculotomy more likely. The modified delivery system is important in these patients, however, because the standard catheter-pod system precludes safe deployment, especially as most significant VSDs require a $17 \mathrm{~mm}$ device. We have also found that a stable position of the device can be ensured by placing a stitch through the fabric of the device as it rests on the right ventricular myocardium. It is uncertain whether the residual defects noted in Fishberger et al's report ${ }^{5}$ were related to the initial positioning of the device, or consequent to displacement during the immediate postoperative manipulations of the heart. The latter occurred in one of our patients, and we recommend this technique in future cases. There have been no overt longterm sequelae to umbrella placement, but it seems prudent to advise vigilant antibiotic prophylaxis against bacterial endocarditis in these patients. Other potential adverse effects, particularly arrhythmias, remain concerns and these patients require careful follow up in this regard.
In conclusion, intraoperative use of a modified Rashkind umbrella is considerably simpler and quicker than performing the analogous procedure in the catheterisation laboratory, and allows safe and effective closure of isolated apical ventricular septal defects.

This work was supported by the Scott Rhodes Research Fund.

1 Kirklin JW,Barrat-Boyes BG. Ventricular septal defects. In Kirklin JW, Barratt-Bayes BC, eds. Cardiac surgery: morphology, diagnostic criteria, natural history, techniques, results and indications. 2nd ed. New York, Churchil Livingstone, 749-824.

2 Serraf A, Lacour-Gayet F, Bruniaux J, Ouakine R, Losay J, Petit J, et al. Surgical treatment of isolated multiple ventricular septal defects, logical approach in 130 cases. $f$ Thorac Cardiovasc Surg 1992;103:437-43.

3 Bridges ND, Perry SB, Keane JF, Goldstein SAN, Mandell $\mathrm{V}$, Mayer JE, et al.Preoperative transcatheter closure of congenital muscular ventricular septal defects. $N$ Engl Med 1991;324:1312-7.

4 Rigby ML, Redington AN. Primary transcatheter umbrella closure of perimembranous ventricular septal defects. $B r$ Heart $\mathcal{F} 1994 ; 72: 368-71$

5 Fishberger SB, Bridges ND, Keane JF, Hanley FL, Jonas $\mathrm{RA}$, Mayer JE, et al. Intraoperative device closure of ven RA, Mayer JE, et al. Intraoperative device closure of ven-

6 Perry SB, Lock JE. Front-loading of the double-umbrella device, a new technique for umbrella delivery for closing cardiovascular defects. Am f Cardiol 1992;70:917-20.

7 Gatzoulis M, Rigby ML, Redington AN. Umbrella occlusion of persistent arterial duct in children under two years. Br Hear $\mathcal{F}$ 1994;72:364-7.

8 Hanna B, Colan SD, Bridges ND, Mayer JE, Castenada AR. Clinical and myocardial status after left ventriculotomy for ventricular septal defect closure (abstract). $\mathscr{f} A m$ Coll Cardiol 1991;17(suppl): 110A.

9 Leca F, Karam J, Vouhe PR, Khoury W, Tamisier D, Bical $O$, et al. Surgical treatment of multiple ventricular septal defects using a biologic glue. $\mathcal{F}$ Thorac Cardiovasc Surg 1994;107:96-102. 